\title{
Elasmobranch cognitive ability: using electroreceptive \\ 2 foraging behaviour to demonstrate learning, habituation and memory in a benthic shark \\ JOEL A. KIMBER* ${ }^{\dagger}$, DAVID W. SIMS ${ }^{\dagger}$, PATRICIA H. BELLAMY*, ANDREW \\ B. GILL* \\ * Department of Environmental Science and Technology, Cranfield University, Cranfield, Bedfordshire, MK43 0AL, UK \\ ${ }^{\dagger}$ Marine Biological Association of the United Kingdom, The Laboratory, Citadel Hill, Plymouth, Devon, PL1 2PB, UK
} 3 


\section{ABSTRACT}

46 Top predators inhabiting a dynamic environment, such as coastal waters, should

47 theoretically possess sufficient cognitive ability to allow successful foraging despite

48 unpredictable sensory stimuli. The cognition-related hunting abilities of marine mammals

49 have been widely demonstrated. Having been historically underestimated, teleost

50 cognitive abilities have also now been significantly demonstrated. Conversely, the

51 abilities of elasmobranchs have received little attention, despite many species possessing

52 relatively large brains comparable to some mammals. The need to determine what, if any,

53 cognitive ability these globally distributed, apex predators are endowed with has been

54 highlighted recently by questions arising from environmental assessments; specifically

55 whether they are able to learn to distinguish between anthropogenic electric fields and 56 prey bioelectric fields.

57 We therefore used electroreceptive foraging behaviour in a model species,

58 Scyliorhinus canicula (small-spotted catshark) to determine cognitive ability by analysing

59 if elasmobranchs are able to learn to improve foraging efficiency and remember learned

60 behavioural adaptations.

61 Positive reinforcement, operant conditioning was used to study catshark foraging

62 behaviour towards artificial, prey-type electric fields (Efields). Catsharks rewarded with

63 food for responding to Efields throughout experimental weeks were compared with

64 catsharks that were not rewarded for responding in order to assess behavioural adaptation

65 via learning ability. Experiments were repeated after a three week interval with 66 previously rewarded catsharks this time receiving no reward and vice versa to assess 67 memory ability. 
Positive reinforcement markedly and rapidly altered catshark foraging behaviour.

69 Rewarded catsharks exhibited significantly more interest in the electrical stimulus than

70 unrewarded catsharks. Furthermore, they improved their foraging efficiency over time by

71 learning to locate and bite the electrodes to gain food more quickly. In contrast,

72 unrewarded catsharks showed some habituation, whereby their responses to the

73 electrodes abated and eventually entirely ceased, though they generally showed no

74 changes in most foraging parameters. Behavioural adaptations were not retained after the

75 interval suggesting learned behaviour was not memorised beyond the interval. Sequences

76 of individual catshark search paths clearly illustrated learning and habituation

77 behavioural adaptation.

78 This study demonstrated learning and habituation occurring after few foraging

79 events and a memory window of between twelve hours and three weeks. These cognitive

80 abilities are discussed in relation to diet, habitat, ecology and anthropogenic Efield

81 sources.

82

83 Key words: Scyliorhinus canicula, Efield, electroreception, behavioural adaptation, 84 search path

85

86

87

88

89

90 


\section{INTRODUCTION}

92 Cognitive ability is fundamental for optimising crucial animal behaviours such as

93 locating and acquiring food and mates, navigating and avoiding predators. It is especially

94 important for animals that inhabit complex, dynamic environments with unpredictable

95 sensory stimuli. Recent research suggests that relative brain size in vertebrates is linked

96 with the ability to adapt and persist in novel and changing environments (Reader and

97 MacDonald 2003; Sol et al. 2005, Maklakov et al. 2011). Coastal environments are

98 particularly changeable, both spatially and temporally, due to the convergence of

99 dynamic marine, freshwater, terrestrial, atmospheric and, increasingly, anthropogenic

100 factors. Organisms that inhabit such an environment should theoretically exhibit

101 behavioural flexibility to enable them to function and survive by adapting to changing

102 conditions and thereby maximise ecological fitness (Dill 1983). Learning and memory

103 are crucial means with which to facilitate such adaptation.

104 The cognitive ability and adaptability of marine mammals when foraging is well

105 supported (Schusterman and Kastak 2002) as evidenced by, for example, development of

106 intentional stranding (Guinet and Bouvier 1995), herding (Similä and Ugarte 1993), vocal

107 learning (Shapiro et al. 2004) and cooperation (Visser et al. 2008). The current, general

108 consensus is that many teleosts (bony fish) also possess significantly more cognitive

109 ability than previously believed (reviewed in Laland et al. 2003; Brown et al. 2006) with,

110 for example, foraging adaptability demonstrated by learning in sticklebacks (Croy and

111 Hughes 1991), salmon (Brown et al. 2003) and mosquito fish (Brown and Braithwaite

112 2005), and memory in trout (Bryan and Larkin 1972) and sticklebacks (Mackney and

113 Hughes 1995). 
114 Conversely, chondrichthyans (cartilaginous fish) have received relatively little

115 attention with respect to cognitive ability. This is surprising given that certain

116 elasmobranchs (sharks, skates and rays) possess brain to body mass ratios that overlap

117 those of some mammals and birds (Demski and Northcutt 1996). Until very recently, the

118 few examples of investigations into elasmobranch cognitive ability were relatively old,

119 and involved visual discrimination to gain food rewards (Clarke 1959 and 1961; Wright

120 and Jackson 1964; Aronson et al. 1967; Graeber and Ebbesson 1972; Graeber et al.

121 1978). More recently, Schluessel and Bleckmann (2005) demonstrated spatial memory of

122 environment in juvenile freshwater stingrays, Kuba et al. (2010) demonstrated tool use in

123 a similar species, Meyer et al. (2010) suggested tiger sharks may use cognitive maps to

124 navigate between distant foraging areas, and Guttridge et al. (2012) demonstrated social

125 learning in juvenile lemon sharks. Based on this limited evidence for cognitive ability in

126 elasmobranchs, we hypothesised that when using their primary sensory mode,

127 electroreception, the cognitive abilities of benthic elasmobranchs would be clearly

128 demonstrable and behaviourally adaptive.

129 Electroreception is the last in a hierarchy of senses utilised by elasmobranchs

130 whilst foraging (Kalmijn 1971); it aids precise location of prey and jaw orientation and

131 has been demonstrated to override all other senses over short distances (Kalmijn 1971;

132 Heyer et al. 1981). It is particularly crucial for the foraging success of benthic species that

133 forage for inconspicuous prey owing to burial, refuging or crypsis (see Tricas and

134 Sisneros 2004 for review). As such, it can be considered fundamental for the feeding

135 success and subsequent somatic and gonadal growth of these predators. Electroreception

136 can also be utilised during the location of and communication with conspecifics, the 
137 detection of predators and possibly in aiding navigation (Tricas and Sisneros 2004).

138 Flexibility in their responses to electric stimuli within their environment via learning and

139 memory should provide tangible ecological benefits to the life processes of these

140 predators. When considered in conjunction with the repeatability of the behaviour under

141 laboratory conditions (Kalmijn 1971), the importance of electroreception makes it an

142 ideal tool to attempt to measure behavioural adaptation. Furthermore, the need to assess

143 the cognitive ability of elasmobranchs has been accentuated recently amid questions

144 raised by environmental assessments in coastal waters worldwide. Given the burgeoning

145 deployment of subsea electric cables (e.g. associated with offshore renewable energy and

146 grid connection development), suggestions of electromagnetically ultra-sensitive

147 elasmobranchs potentially being affected have arisen (Gill et al. 2005; Sutherland et al.

148 2008). The principal question relates to whether the elasmobranchs will be able to learn

149 about electrical stimuli to enable them to distinguish between those that provide an

150 energetic return (such as prey located via their bioelectric fields) and those that are

151 anthropogenic in origin and that provide no food return (Kimber et al 2011).

152 The objective of this study was therefore to investigate the ability of a model

153 species of benthic elasmobranch, the small-spotted catshark (Scyliorhinus canicula), to

154 learn to adapt its electroreceptive foraging behaviour towards profitable (in terms of food 155 gain) and non-profitable (i.e. no food gain) electrical stimuli and remember learned 156 adaptations. Such results would support the growing body of evidence that cognitive 157 ability is beneficial in novel and changing environments among a variety of predators, 158 and provide useful information for environmental assessments. 
In this context, laboratory studies were designed to study catshark behaviour

160 using operant conditioning. Experiments investigated the foraging behaviour of catsharks

161 rewarded with food for operant responses to an electrical stimulus. Contrasting treatment

162 experiments were undertaken during which no food rewards were provided for responses

163 to the electrical stimulus. Experiments were then repeated after an interval with

164 previously rewarded catsharks receiving no food and vice versa to assess memory.

166 METHODS

167 Animals and Apparatus

168 Twenty four size-matched (mean total length $=61.8 \pm 4.8 \mathrm{~cm}$ standard deviation),

169 mixed-sex small-spotted catsharks (S. canicula) were caught on a Marine Biological

170 Association of the U.K. (MBA) research vessel off Plymouth, southwest England (station

171 L4: $50^{\circ} 15^{\prime} \mathrm{N}, 4^{\circ} 13^{\prime} \mathrm{W}$ ). They were randomly assigned to one of four groups (1 to 4 ) and

172 tagged just below their dorsal fin with different coloured, individually numbered T-bar

173 anchor tags (FLOY TAG Inc., Seattle, Washington USA) following licensed UK Home

174 Office animal welfare regulations. Catsharks were maintained in 2,242 litre holding

175 aquaria ( $1.83 \mathrm{~m}$ diameter $\mathrm{x} 0.43 \mathrm{~m}$ depth) supplied by a sea water flow and return system

176 at the MBA in which they acclimatised for three weeks. Twice weekly, they were each

177 fed a $20 \mathrm{~g}$ food ration equivalent to $3 \%$ wet body mass per feed to standardise feeding

178 motivation (Sims and Davies 1994). Food consisted of mixed squid (Loligo forbesi),

179 whiting (Merlanguis merlangus) and marine pellets with liposome spray (New Era

180 Aquaculture Ltd., Thorne, UK). 
182 prey-type electric fields (sensu Kimber et al. 2009). A trap-door mechanism and hidden

183 food compartment were attached to the underside of an opaque, raised and gently ramped

184 electrode plate. The food compartment was positioned against the plate and sealed with

185 silicone gel to prevent food scent seepage. A hydraulic system of BD Luer Lok syringes

186 and Nalgene 380 PVC tubing allowed the food compartment to be opened and closed

187 remotely, smoothly, quickly and silently by the observer. This permitted presentation of

188 food rewards to catsharks in close proximity to the dipole, immediately after a response

189 to an electric field, and with minimal disturbance.

191 Experimental Procedure

192 Six 792 litre, acrylic aquarium tanks supplied with filtered seawater were used as

193 behavioural arenas $(1.65 \mathrm{~m} \mathrm{~L} \times 0.80 \mathrm{~m} \mathrm{~W} \times 0.60 \mathrm{~m} \mathrm{D})$. The six catsharks from group 1

194 were transferred to randomly chosen arenas (one catshark per arena) and allowed to

195 acclimatise for 60 hours. Each catshark was then presented with an Efield produced by a

$1969 \mu \mathrm{A}$ direct current twice per day for five days, a total of 10 experimental sessions,

197 forming an experimental week. The Efield was chosen due to its similar strength to prey

198 bioelectric fields and demonstrated elicitation of voluntary (operant) feeding responses in

199 these benthic sharks (Kalmijn 1971; Kalmijn 1972). These feeding responses consist of

200 rapidly turning towards and biting upon the electrodes (often repeatedly) once the Efield

201 is detected. Three randomly selected catsharks were positively reinforced by rewarding

202 them with offer of approximately $1.3 \mathrm{~g}$ of food immediately after their first bite upon the

203 electrodes in each experimental session. Catsharks not consuming all of their rewards 
204 were fed the remainder of their weekly $13 \mathrm{~g}$ ration after the experimental week was

205 completed. This reduced feeding ration (approximately $2 \%$ wet body mass per week:

206 Sims and Davies 1994) ensured satiation was not reached and hunger and normal

207 foraging behaviour persisted during the week. The other three catsharks acted as

208 contrasting treatments, whereby they were not rewarded for biting the electrodes, but

209 were instead fed a $13 \mathrm{~g}$ food ration after the experimental week was completed.

210 On completion of the experimental week, the group 1 catsharks were transferred

211 back to the holding aquaria and replaced with the catsharks from group 2. After 60 hours

212 acclimatisation, group 2 then underwent a similar experimental week. This procedure was

213 repeated for groups 3 and 4. Once group 4's experimental week was complete, each

214 group (1 to 4 in turn) then underwent a second experimental week (with each catshark in

215 different, randomly assigned arenas), similar except that those previously rewarded were

216 not rewarded and vice versa. There was therefore a three week interval between each

217 group's two experimental weeks.

218 Prior to each particular experimental session, a salt-bridge apparatus was

219 introduced into a randomly chosen arena, and at a randomly chosen end (to ensure

220 catsharks were not simply learning to associate the food with a particular location), with

221 the power switched off and water flow halted to allow the catsharks to settle down. After

22220 minutes, the power was switched on and $20 \mathrm{ml}$ of food scent (sieved squid and whiting

223 added to water) was introduced into the arena approximately $7.5 \mathrm{~cm}$ from the dipole.

224 Since one of the first hierarchical senses used during foraging by elasmobranchs is

225 olfaction (Hodgson and Mathewson 1971), it is necessary to use a dose of scent to

226 stimulate foraging behavior and attract the catsharks towards the electrode plate (sensu 
227 Kalmijn 1971). Once in close proximity of the electrodes, electroreception is known to 228 override all other senses. For the relatively small, benthic $S$. canicula this predominantly

229 occurs within approximately $5 \mathrm{~cm}$ to $10 \mathrm{~cm}$ (Dawson et al. 1980; Kimber et al. 2009) in 230 comparison to up to 30 $\mathrm{cm}$ for larger, pelagic species (Kalmijn 1971; Heyer et al. 1981).

231 Sessions lasted for no more than 15 minutes and were recorded using overhead 232 cameras. The following hierarchical response variables of each catshark were compiled 233 by reviewing video footage: (a) the number of times the catsharks passed within $5-\mathrm{cm}$ of 234 the electrodes, (b) the latency of turns towards and bites upon the electrodes, (c) the 235 frequency of turns towards and bites upon the electrodes, (d) after which bite (i.e. first, 236 second $e t c$.) and what latency a food reward was taken (note rewards were not always 237 taken immediately), and finally (e) the search paths the catsharks undertook from their 238 starting position (when scent detected) to their first response at the electrode dipole. The 239 latter were traced from video footage on a large monitor. These traces were then 240 converted to JPEG files using an HP Designjet 815mfp scanner and subsequently 241 converted to polyline shape files and geo-referenced to arena size using ArcGIS software.

242 An index of the path directness to the dipole was then calculated by dividing search path 243 lengths by the direct distance between starting position and the electrodes.

244 Upon completion of all experiments, tags were removed from catsharks and the 245 attachment points treated. The catsharks were held in holding aquaria and after a short 246 period of observation were certified for release to the sea off Plymouth. 


\section{Data analysis}

251 Statistica 8.0 and Genstat 10.0 software were used to run the statistical models

252 that analysed differences in electroreceptive foraging behavioural parameters (a to e)

253 between rewarded $(\mathrm{R})$ and not rewarded $(\mathrm{N})$ catsharks, between experimental weeks 1

254 and 2, and also changes in the parameters throughout experimental sessions (i.e. within

255 experimental weeks). Depending upon the hypothesis being tested and data type (count,

256 continuous or path directness index), either hierarchical generalized linear mixed models

257 (HGZLMM), hierarchical general linear models (HGLM) or general linear models

258 (GLM) were used with relevant distributions (poisson, log link, identity or normal). Fixed

259 effects were reward (yes or no) and experimental week (1 or 2) for tests between

260 rewarded and unrewarded catsharks and between experimental weeks 1 and 2, and

261 experimental session (1 to 10) or individual number for tests within experimental weeks.

262 This ensured that each data point for each catshark was used only once during each

263 analysis. If replication (non-independence) was not already accounted for within these

264 models, the relevant random effects (individual number and/or session) or continuous

265 predictors (session) were also used. These carefully formulated models robustly and

266 powerfully dealt with the complex data to generate accurate descriptions of biologically

267 relevant effects (sensu Nakagawa and Cuthill 2007).

268 Estimates of effects generated by modeling and presented here represent either

269 relative differences between means (whereby rewarded catshark effects are compared to

270 the zero reference, unrewarded catsharks between experimental weeks) or regression

271 coefficients (within experimental weeks). The latter were back-transformed to the units of

272 original measurement to enable fitted curve plots to be produced (raw data was omitted 
273 owing to the effects of individual catsharks being partially confounded with experimental

274 session). For all model results reported, the distributions of residuals (using

275 transformations as required), were close to Normal and therefore the models were

276 assumed to be satisfactory. Residual degrees of freedom ranged between approximately

277215 and 460 unless otherwise stated.

278

279 RESULTS

280 Learning and habituation

$281 \quad$ Averaged over all ten experimental sessions, rewarded catsharks passed within 5-

$282 \mathrm{~cm}$ of the electrodes significantly more than unrewarded catsharks (relative difference

283 between means $=0.725$, standard error $($ S.E. $)=0.141, t=5.15, P \ll 0.0001)$.

284 Throughout an experimental week, the high number of passes rewarded catsharks made

285 before their first response to the electrodes significantly decreased (regression coefficient $286=-0.0678$, S.E. $=0.0148, t=4.59 ; P<0.001$; Figure 2$)$. There was no change in the low

287 number of passes unrewarded catsharks made before their first response to the electrodes

288 (regression coefficient $=-0.0001$, S.E. $=0.0328, t=0.00 ; P=1.0 ;$ Figure 2).

289 Throughout an experimental week, the time latency of first response to the 290 electrodes of rewarded catsharks significantly decreased (regression coefficient $=$ -

2910.0677 , S.E. $=0.0274, t=2.47, P=0.014$; Figure 3 ). There was no change in the time 292 latency of first response of unrewarded catsharks (regression coefficient $=-0.0039$, S.E. $=$ $2930.0366, t=0.11, P=0.91$; Figure 3). Averaged over all ten experimental sessions, 294 rewarded catsharks turned towards and bit the electrodes significantly more than 295 unrewarded catsharks (relative different between means $=0.866$ and 0.851, S.E. $=0.162$ 
297 experimental week, the higher number of turns and bites made by rewarded catsharks 298 significantly decreased (regression coefficient $=-0.0547$ and -0.0940, S.E. $=0.00816$ and $2990.0114, t=6.70$ and 8.27 respectively, both $P<0.0001$; Figure 4). So, too, did the lower 300 number of turns and bites made by unrewarded catsharks, but more sharply (regression 301 coefficient $=-0.151$ and -0.205, S.E. $=0.0140$ and $0.0206, t=10.77$ and 9.93 302 respectively, both $P<0.0001$; Figure 4), such that on average, they ceased to bite upon 303 the electrodes altogether after approximately six or seven experimental sessions.

304 As the catsharks swam and searched for food rapidly, they did not always manage 305 to take food rewards immediately after being offered them following their first bite upon 306 the electrodes. If this was the case, however, they would almost invariably turn back 307 swiftly (and repeatedly) to bite the electrodes again (rewarded catsharks responded to the 308 electrodes greater than once in more than $97 \%$ of treatments). The bite after which they 309 took the food reward was therefore not necessarily the first. The bite number and time 310 after which rewarded catsharks managed to attain the food reward throughout an 311 experimental week decreased significantly (regression coefficient $=-0.0716$ and -0.0844 ,

312 S.E. $=0.0182$ and $0.0294, t=3.94$ and 2.87 respectively, $P=0.0001$ and 0.004 313 respectively; Figure 5). The search paths undertaken by rewarded catsharks throughout an 314 experimental week also significantly decreased (regression coefficient $=1.904$, S.E. $=$ $3150.0288, S S=5.91 ; P<0.019$; Figure 6 and 7). In contrast, on average, the paths 316 undertaken by unrewarded catsharks did not change throughout an experimental week 317 (regression coefficient $=1.61$, S.E. $=0.0347, S S=0.137 ; P=0.69 ;$ Figure 6 and 7 ). 


\section{Memory}

321 Table 1 shows that when rewarded and unrewarded catshark data were grouped

322 together and compared between experimental weeks before and after the three week

323 interval, there were no significant differences in any behavioural parameters other than a

324 slight difference in the latency of first response to the electrodes. Neither were any

325 interactions observed between reward (yes/no) and week (1 and 2) for any of the

326 parameters (Table 1). Therefore, on average, foraging behaviour was independent of

327 whether a catshark was rewarded before the interval and unrewarded after the interval or

328 vice versa. These results suggest that behavioural alterations were not retained beyond the 329 interval.

\section{DISCUSSION}

332 All catsharks were of similar size and maturity, from the same geographic 333 location, acclimatised to the study conditions for equal time periods and fed on equal, 334 minimum rations. Previous experience and initial motivation to feed was therefore 335 assumed to be standardised among experimental animals. Rewarded catsharks 336 consistently foraged and ingested rewards suggesting the small size of rewards prevented 337 satiation and ensured continued motivation to respond to feeding opportunities. 338 Unrewarded catsharks also showed continued, but not increasing motivation to feed.

339 Water temperature varied with natural conditions during experimental procedures

340 (18.22 ${ }^{\circ} \mathrm{C}+/-0.98$ S.D.). However, this small level of variation has previously been

341 shown to have little effect on electroreceptive behaviour (Kimber et al. 2009). All

342 experimental animals were subjected to the same experimental conditions in stable, 
343 predator free environments and the large sample size and powerful modelling provided

344 the confidence that differences and trends observed were accountable to the experience

345 and behavioural flexibility of the catsharks.

346 Reinforcement of the operant foraging response to an electric stimulus by

347 rewarding with food clearly altered the behaviour of catsharks. As would be expected,

348 rewarded catsharks showed more interest in the electrodes than the contrasting treatment,

349 unrewarded catsharks, demonstrated by more passes by, turns towards and bites upon the

350 electrodes. Crucially, rewarded catsharks exhibited a number of behavioural alterations

351 that suggest they were learning how to obtain food. The number of times they passed

352 within close proximity of the electrodes before responding to them and the time latency

353 of first response decreased. The bite number and time after which they managed to

354 acquire the food reward from the trap door compartment decreased. Therefore, they did

355 not need to respond further, and consequently, the number of times they turned towards

356 and bit the electrodes also decreased. Furthermore, the length of search path they

357 employed to first respond to the electrodes also decreased (see Figure 7 for clear

358 examples of individual catshark search paths decreasing). Effectively, these results

359 strongly suggest these catsharks were learning that when stimulated to forage, by rapidly

360 locating the electrodes and biting them, food would appear in close proximity of the

361 electrodes. Furthermore, the substantial changes in behaviour elicited by so few rewards

362 (a maximum of ten per catshark, but often requiring just a few) demonstrate impressively

363 rapid learning. Behavioural alterations improved the foraging efficiency of these

364 catsharks over time and theoretically would have reduced energetic costs per unit food 365 attained. 
366 Conversely, in the contrasting treatment, unrewarded catsharks exhibited less

367 interest in the electrodes, and less behavioural adaptation; no change in the number of

368 times they passed in close proximity of the electrodes, no change in latency to respond to

369 the electrodes and no change in the length of their search paths. They did, however,

370 markedly reduce the amount of times they turned towards and bit upon the electrodes

371 throughout an experimental week (even more so than their rewarded counterparts), and

372 even stopped biting altogether, which suggests they habituated to the electric stimulus

373 since they did not obtain any food by biting it. Theoretically, such adaptations would also

374 have reduced energetic and opportunity costs by reducing wasted effort. Figure 7 shows

375 examples of typical search path sequences of unrewarded catsharks, with no apparent

376 pattern or clearly habituating (eventually failing to respond to the electrodes and scent).

377 Whilst the results clearly demonstrate striking learning in the catsharks, according

378 to classical cognition theory there is a possibility that non-contingency might explain

379 some behavioural alterations (differences elicited by the food rather than being a

380 consequence of the contingency between bites to the electrodes and subsequent food

381 reward). A further control condition in which food is delivered non-contingently might

382 help to address this question, ideally involving a yoked procedure whereby two catsharks

383 in separate tanks are both offered concurrent rewards when one (the executive) responds

384 to an Efield, regardless of the other, yoked catshark's responses (sensu Church 1964).

385 Such a control would be a significant challenge in itself, especially considering the 386 complex, hierarchical stimulus modality inherent when studying elasmobranch

387 electroreceptive foraging behaviour. However, since the experiment was designed to

388 involve operant conditioning under positive reinforcement and to investigate ability to 
389 learn to distinguish between anthropogenic Efields and prey bioelectric fields in the

390 natural environment, the behavioural adaptations observed demonstrate significant

391 learning nonetheless.

392 The average learning behavioural adaptations revealed by statistical analysis were

393 exhibited by most, but not all catsharks. For example, 70 and $76 \%$ of rewarded catsharks

394 exhibited trends associated with learning; decreasing reward attainment bite time and bite

395 number respectively. Hence 30 and $24 \%$ did not exhibit such trends associated with

396 learning. Therefore learning ability apparently varied between individuals. However, both

397 sexes exhibited similar behavioural adaptations. It is possible that differences between the

398 adaptations of the sexes might become apparent if groups of catsharks were studied,

399 rather than individuals, since sexual conflict (specifically male harassment and female

400 avoidance) have been demonstrated to affect foraging behaviour (Kimber et al. 2009).

401 The fact that none of the learned and habituated behaviours were continued after a

402 three week interval and that behaviour levels were independent of whether rewards were

403 offered before or after the interval suggests that the memory window for these

404 elasmobranchs is less than three weeks. Having returned to the experimental arenas after

405 the interval, the catsharks behaved as if they had not been subjected to the previous

406 experimental sessions, regardless of whether rewarded or unrewarded. They then began

407 to swiftly adapt their foraging behaviour over the subsequent experimental weeks 408 accordingly.

409 Like many other marine predators, elasmobranchs often inhabit highly variable,

410 shallow coastal waters (Compagno et al. 2005) and many are therefore opportunistic

411 predators (Lyle 1983; Ellis et al. 1996; Laptikhovsky et al. 2001). When considering 
412 populations of these elasmobranchs in their natural habitats, the impressive cognitive

413 abilities demonstrated here make ecological sense. In essence, the sharks seem able to

414 rapidly learn to improve their electroreceptive foraging efficiency towards profitable

415 stimuli (in terms of food gain) over short periods (and presumably within small spatial

416 scales). Equally, within similar temporal and spatial limits, they can rapidly habituate to

417 (or learn to ignore) non-profitable stimuli (i.e. no food gain). This swift flexibility would

418 therefore allow, for example, the predators to focus their efforts on easily caught, edible

419 or nutritious prey (Dill 1983; Stephens and Krebs 1986; Kaiser et al. 1992). Similarly,

420 efforts towards inedible, nutrient lacking and difficult to catch prey could be reduced,

421 which would permit focussing elsewhere and minimising missed opportunities. For

422 example, greater modification of foraging behaviour has been demonstrated in crabs

423 (Micheli 1997) and sticklebacks (Girvan and Braithwaite 1998) when encountering

424 variable prey in less stable habitats. Greater adaptability, inferred from larger brain size,

425 has also been suggested to enable success in novel, complex or variable environments in

426 passerine birds (Maklakov et al. 2011), primates (Reader and MacDonald 2003) and

427 marine mammals (Kuczaj et al. 2009).

428 The coastal zone is especially variable due to both natural and anthropogenic

429 factors. In such an environment, therefore, remembering these electroreceptive foraging 430 adaptations over longer temporal periods and larger spatial scales may not be of benefit

431 (sensu Hirvonen et al. 1999). Possessing a memory window of less than three weeks for

432 these skills is reasonable when considering prey diversity and distributions, in addition to 433 physical habitat, may well change over relatively short time periods and over small 434 distances. It would be interesting to determine exactly where this memory window lies in 
435 these benthic elasmobranchs. The results suggest it lies somewhere between 12 hours

436 (learned behaviour was obviously remembered between experimental sessions each day)

437 and 3 weeks (the experimental interval period). Longer memories have been

438 demonstrated in teleost fish inhabiting relatively stable environments (e.g. up to 6 months

439 in trout: Bryan and Larkin 1972; 3 months in cod: Nilsson et al. 2008) compared to

440 shorter memories in those inhabiting more variable environments (e.g. 3 hours in paradise

441 fish: Csanyi et al. 1989; from minutes to days in sticklebacks: Mackney and Hughes

$442 \quad$ 1995; Hughes and Blight 1999).

443 Cognitive abilities are also likely to vary between elasmobranch species. For

444 example, one may expect better memory windows in species inhabiting more stable

445 habitats than more variable habitats (c.f. teleost fish; Odling-Smee and Braithwaite 2003).

446 Inter-specific differences in visual learning have previously been observed between

447 lemon and nurse (Clarke 1959) and lemon and bull sharks (Wright and Jackson 1964).

448 Variation in brain to body mass ratios and in the relative mass of the major brain

449 divisions can be used to postulate the capacities of different species' senses and cognition

450 (Demski and Northcutt 1996). Scyliohrinus canicula have average brain to body mass

451 ratios (Ridet et al. 1973) compared to higher and lower examples such as scalloped

452 hammerheads (Sphyrna lewini) and Greenland sharks (Somniosus microcephalus)

453 respectively (Northcutt 1978; Myagkov 1991). Interestingly, the former range widely

454 throughout a number of markedly different coastal habitats, while the latter remain

455 predominantly in cold, stable, deep arctic waters (Compagno et al. 2005).

456 In addition to ecological considerations, the results of this study also have

457 important implications regarding growing interest in possible interactions between 
458 electroreceptive fish and anthropogenic sources of Efields in the coastal environment that

459 are within the range detectable and attractive to elasmobranchs (such as subsea cables:

460 Gill et al. 2005; Gill and Kimber 2005; Sutherland et al. 2008; Boehlert and Gill 2010).

461 Given the results of this study, it appears that within small temporal and spatial scales the

462 sharks may be able to learn to ignore anthropogenic Efields and focus upon bioelectric

463 fields by behavioural adaptation (assuming they can differentiate the sources; Kimber et

464 al. 2011). However, they may well forget these adaptations over larger scales (e.g. when

465 travelling between foraging areas) and respond to both types of Efield again. The balance

466 between learning and forgetting would ultimately dictate long term effects on individual

467 success and ecological fitness.

468 In conclusion, we have measured rapid learning and habituation adaptation but 469 relatively short memory in a fundamental behaviour for a model, benthic elasmobranch

470 species. These cognitive abilities ideally suit a predator inhabiting a variable environment

471 by improving foraging efficiency, but preventing missed opportunities, and support

472 studies of other taxa that suggest relatively large brain size and behavioural adaptability

473 correlates with habitat stability.

475 ACKNOWLEDGEMENTS

476 We thank J. Rundle for animal husbandry, K. Atkins for technical assistance, J. Mavin for

477 help designing and constructing trap-door mechanism, I. Truckell for scanning assistance,

478 B. Clutterbuck for assistance with ArcGIS, P. Rendle, P. Masterson, M. McHugh, J. Filer,

479 V. Wearmouth, and the crew of R.V. Plymouth Quest for assistance with specimen

480 collection. We also thank the anonymous reviewers for their comments. JAK was 
481 supported by a Fisheries Society of the British Isles funded studentship and by Cranfield 482 University. DWS was supported by a Natural Environment Research Council (NERC)

483 funded Marine Biological Association (MBA) Fellowship and by the NERC Oceans 2025

484 Strategic Research Programme (Theme 6 Science for Sustainable Marine Resources). 485 486

487 REFERENCES

488 Aronson LR, Aronson FR, Clarke E (1967) Instrumental conditioning and light-dark 489 discrimination in young nurse sharks. B Mar Sci 17:249-256

490

491 Boehlert GW, Gill AB (2010) Environmental and ecological effects of ocean renewable 492 energy development - a current synthesis. Oceanography 23:68-81

494 Brown C, Braithwaite VA (2005) Effects of predation pressure on the cognitive ability of 495 the poeciliid Brachyraphis episcopi. Behav Ecol 16:482-487

496

497 Brown C, Markula A, Laland K (2003) Social learning of prey location in hatchery reared 498 Atlantic salmon. J Fish Biol 63:738-745

499

500 Brown C, Laland K, Krause J (2006) Fish cognition and behaviour. Blackwell Publishing 501 Ltd, Oxford

502 
503 Bryan JE, Larkin PA (1972) Food specialization by individual trout. Journal Bull Fish

504 Res Board Can 29:1615-1624

505

506 Centre for Marine and Coastal Studies (CMACS) (2003) A baseline assessment of

507 electromagnetic fields generated by offshore wind farm cables (COWRIE Stage 1).

508 Report number COWRIE-EMF-01-2002

509

510 Church RM (1964) Systematic effect of random error in the yoked control design.

511 Psychol Bull 62(2):122-131

512

513 Clark E (1959) Instrumental conditioning of lemon sharks. Science 130:217-218

514

515 Clark E (1961) Visual discrimination in lemon sharks. In: Tenth Pacific science congress,

516 University of Hawaii, Honolulu, USA, 21 August - 6 September 10:175-176

517

518 Compagno L, Dando M, Fowler, S (2005) Sharks of the world. HarperCollins Publishers

519 Ltd, London

520

521 Croy MI, Hughes RN (1991) The role of learning and memory in the feeding behaviour

522 of the fifteen-spined stickleback, Spinachia spinachia L. Anim Behav 41:149-159

523

524 Csanyi V, Csizmadia G, Miklosi A (1989) Long-term memory and recognition of another

525 species in the paradise fish. Anim Behav 37:908-911 
527 Dawson BG, Heyer GV, Eppi R, Kalmijn AJ (1980) Field experiments on electrically

528 evoked feeding responses in the dogfish shark, Mustelus canis. Biol Bull 159:482

529

530 Demski LS, Northcutt RG (1996) The brain and cranial nerves of the white shark: An

531 evolutionary perspective. In: Klimley AP and Ainley DG (eds) White sharks: The biology

532 of Carcharadon carcharias. Academic Press, pp 121-131

533

534 Dill LM (1983) Adaptive flexibility in the foraging behavior of fishes. Can J Fish Aquat

535 Sci 40:398-408

536

537 Ellis JR, Pawson MG, Shackley SE (1996) The comparative feeding ecology of six

538 species of shark and four species of ray (Elasmobranchii) in the North-east Atlantic. J

539 Mar Biol Ass UK 76:89-106

540

541 Gill AB, Kimber JA (2005) The potential for cooperative management of elasmobranchs

542 and offshore renewable energy development in UK waters. J Mar Biol Ass UK 85:1075-

$543 \quad 1081$

544

545 Gill AB, Gloyne-Phillips I, Neal KJ, Kimber JA (2005) The potential effects of

546 electromagnetic fields generated by sub-sea power cables associated with offshore wind

547 farm developments on electrically and magnetically sensitive marine organisms.

548 (COWRIE stage 1.5). Report number COWRIE EMF 06-2004 
550 Gill AB, Huang Y, Gloyne-Philips I, Metcalfe J, Quayle V, Spencer J, Wearmouth V

551 (2009) COWRIE 2.0 Electromagnetic Fields (EMF) Phase 2: EMF-sensitive fish

552 response to EM emissions from sub-sea electricity cables of the type used by the offshore

553 renewable energy industry. Commissioned by COWRIE Ltd. Report number COWRIE-

554 EMF-1-06

555

556 Girvan JR, Braithwaite VA (1998) Population differences in spatial learning in three-

557 spined sticklebacks. Proc R Soc Lond B 265:913-918

558

559 Graeber RC, Ebbesson SO (1972) Visual discrimination learning in normal and tectal-

560 ablated nurse sharks (Ginglymostoma cirratum). Comp Biochem Physiol A 42:131-139

561

562 Graeber RC, Ebbesson SO, Jane JA (1978) Visual discrimination following partial

563 telencephalic ablations in nurse sharks (Ginglymostoma cirratum). J Comp Neurol $564 \quad 180: 325-344$

565

566 Guinet C, Bouvier J (1995) Development of intentional stranding hunting techniques in

567 killer whale (Orcinus orca) calves at Crozet Archipelago. Can J Zool 73:27-33

568

569 Guttridge TL, van Dijk S, Stamhuis EJ, Krause J, Gruber SH, Brown C (2012) Social

570 learning in juvenile lemon sharks, Negaprion brevirostris. Anim Cogn 16(1):55-64 
572 Heyer GW, Fields MC, Fields RD, Kalmijn AJ (1981) Field experiments on electrically

573 evoked feeding responses in the pelagic blue shark, Prionace glauca. Biol Bull 161:345-

$574 \quad 346$

575

576 Hirvonen H, Ranta E, Rita H, Peuhkuri (1999) Significance of memory properties in prey

577 choice decisions. Ecol Model 115:177-189

578

579 Hodgson ES, Mathewson RF (1971) Chemosensory orientation in sharks. Ann NY Acad

$580 \quad$ Sci $188: 175-182$

581

582 Hughes RN, Blight CM (1999) Algorithmic behaviour and spatial memory are used by

583 two intertidal fish species to solve the radial maze. Anim Behav 58:601-613

584

585 Kaiser MJ, Westhead AP, Hughes RN, Gibson RN (1992) Are digestive characteristics

586 important contributors to the profitability of prey? A study of diet selection in the fifteen-

587 spined stickleback, Spinachia spinachia (L.). Oecologia 90:61-69

589 Kalmijn AJ (1971) The electric sense of sharks and rays. J Exp Biol 55:371-383

590

591 Kalmijn AJ (1972) Bioelectric fields in sea water and the function of the ampullae of

592 Lorenzini in elasmobranch fishes. SIO Ref Ser 72-83:1-21

593 
594 Kimber JA, Sims DW, Bellamy PH, Gill AB (2009) Male-female interactions affect

595 foraging behaviour within groups of small- potted catshark, Scyliorhinus canicula. Anim

596 Behav 77:1435-1440

597

598 Kimber JA, Sims DW, Bellamy PH, Gill AB (2011) The ability of a benthic 599 elasmobranch to discriminate between biological and artificial electric fields. Mar Biol $600 \quad 158(1): 1-8$

601

602 Kuba MJ, Byrne RA, Burghardt GM (2010) A new method for studying problem solving 603 and tool use in stingrays (Potamotrygon castexi). Anim Cogn 13(3):507-513

604

605 Kuczaj SA, Gory JD, Xitco MJ (2009) How intelligent are dolphins? A partial answer 606 based on their ability to plan their behavior when confronted with novel problems. Jap J

607 Anim Psychol 59:99-115

608

609 Laland KN, Brown C, Krause J (2003) Learning in fishes: from three-second memory to 610 culture. Fish Fish 4:199-202

611

612 Laptikhovsky VV, Arkhipkin AI, Henderson AC (2001) Feeding habits and dietary 613 overlap in spiny dogfish Squalus acanthias (Squalidae) and narrowmouth catshark 614 Schroederichthys bivius (Scyliorhinidae). J Mar Biol Ass UK 81:1015-1018

615 
616 Lyle JM (1983) Food and feeding habits of the lesser spotted dogfish, Scyliorhinus

617 canicula (L.), in Isle of Man waters. J Fish Biol 23:725-737

618

619 Mackney PA, Hughes RN (1995) Foraging behaviour and memory window in 620 sticklebacks. Behaviour 132:1231-1253

621

622 Maklakov AA, Immler S, Gonzalez-Voyer A, Ronn J, Kolm N (2011) Brains and the 623 city: big-brained passerine birds succeed in urban environments. Biol Lett 7(5):730-732

624

625 Meyer CG, Papastamatiou YP, Holland KN (2010) A multiple instrument approach to 626 quantifying the movement patterns and habitat use of tiger (Galeocerdo cuvier) and 627 Galapagos sharks (Carcharhinus galapagensis) at French Frigate Shoals, Hawaii. Mar 628 Biol 157:1857-1868

629

630 Micheli F (1997) Effects of experience on crab foraging in a mobile and a sedentary 631 species. Anim Behav 53:1149-1159

632

633 Myagkov NA (1991) The brain sizes of living elasmobranchii as their organization level 634 indicator. I. General analysis. J Brain Res 32:553-561

635

636 Nakagawa S, Cuthill IC (2007) Effect size, confidence interval and statistical 637 significance: a practical guide for biologists. Biol Rev 82:591-605

638 
639 Nilsson J, Kristiansen TS, Fosseidengen JE, Ferno A, van den Bos R (2008) Learning in

$640 \operatorname{cod}$ (Gadus morhua): long trace interval retention. Anim Cogn 11:215-222

641

642 Northcutt RG (1978) Brain organization in cartilaginous fishes. In: Hodgson ES and

643 Mathewson RF (eds) Sensory biology of sharks, skates and rays. U.S. Office of Naval

644 Research, Arlington, Virginia, pp 117-193

645

646 Odling-Smee L, Braithwaite VA (2003) The influence of habitat stability on landmark

647 use during spatial learning in the three-spined stickleback. Anim Behav 65:701-707

648

649 Reader SM, MacDonald K (2003) Environmental variability and primate behavioural

650 flexibility. In: Reader SM and Laland KN (eds) Animal innovation Oxford University

651 Press, Oxford, UK

652

653 Ridet J-M, Bauchot R, Delfini C, Platel R, Thireau M (1973) L'encephale de Scyliorhinus

654 canicula (Linne) (Chondrichthyes, Slacii, Scyliorhinidae). Recherche d'une grandeur de

655 reference pour des etudes quantitatives. Cah Biol Mar 14:11-28

656

657 Schluessel V, Bleckmann H (2005) Spatial memory and orientation strategies in the 658 elasmobranch Potamotrygon motoro. J Comp Physiol A 191:695-706

659

660 Schusterman RJ, Kastak D (2002) Problem solving and memory. In: Hoelzel R (ed)

661 Marine mammal biology: an evolutionary approach. Blackwell Science Ltd, pp 371-388 
664 Shapiro AD, Slater PIB, Janik VM (2004) Call usage learning in gray seals (Halichoerus

665 grypus). J Comp Physiol 118:447-54

668 Similä T, Ugarte F (1993) Surface and underwater observations of cooperatively feeding

669 killer whales in Northern Norway. Can J Zool 71:1494-1499

670

671 Sims DW, Davies SJ (1994) Does specific dynamic action (SDA) regulate return of 672 appetite in the lesser spotted dogfish, Scyliorhinus canicula? J Fish Biol 45:341-348

673

674 Sol D, Bacher S, Reader SM, Lefebvre L (2008) Brain size predicts the success of 675 mammal species introduced into novel environments. Am Nat 172:S63-S71

676

677 Stephens DW, Krebs JR (1986) Foraging theory. Princeton University Press, Princeton, 678 New Jersey

679

680 Sutherland WJ, Bailey MJ, Bainbridge IP, Brereton T, Dick JTA, Drewitt J, Gilder PM, 681 Green RE, Heathwaite AL, Johnson SM, MacDonald DW, Mitchell R, Osborn D, Owen 682 RP, Pretty J, Prior SV, Prosser H, Pullin AS, Rose P, Stott A, Tew T, Thomas CD, 683 Thompson DBA, Vickery JA, Walker M, Walmsley C, Warrington S, Watkinson AR, 684 Williams RJ, Woodroffe R, Woodroof HJ (2008) Future novel threats and opportunities 685 facing UK biodiversity identified by horizon scanning. J Appl Ecol 45:821-833 686 
687 Tricas TC, Sisneros JA (2004) Ecological functions and adaptations of the elasmobranch 688 electrosense. In: von der Emde G, Mogdans J and Kapoor BG (eds) The senses of fishes:

689 Adaptations for the reception of natural stimuli. Narosa Publishing House, New Delhi, 690 India, pp 308-329

691

692 Visser IN, Smith TG, Bullock ID, Green GD, Carlsson OG, Imberti S (2008) Antartic 693 peninsula killer whales (Orcinus orca) hunt seals and a penguin on floating ice. Mar 694 Mammal Sci 24:225-234

695

696 Wright T, Jackson R (1964) Instrumental conditioning of young sharks. Copeia 2:409$697 \quad 412$ 


\section{TABLES}

Table 1. Results when comparing hierarchical response parameters between week before (1) and week after (2) a three week interval and interactions between reward $(\mathrm{R})$ and not-reward $(\mathrm{N})$ and week 1 and 2

\begin{tabular}{|c|c|c|c|c|c|c|c|c|}
\hline \multirow[t]{2}{*}{ Behaviour parameter } & \multicolumn{4}{|c|}{ Week 1 and 2} & \multicolumn{4}{|c|}{ Interaction $\mathrm{R} / \mathrm{N}$ and Week $1 / 2$} \\
\hline & Effect* $*$ & S.E. & Stat** & $P$ & Effect* & S.E. & Stat** & $P$ \\
\hline Passes within $5 \mathrm{~cm}$ & -0.117 & 0.149 & 0.78 & 0.44 & 0.169 & 0.260 & 0.65 & 0.52 \\
\hline Latency to $1^{\text {st }}$ response & -0.487 & 0.245 & 1.99 & 0.05 & 0.582 & 0.387 & 1.90 & 0.21 \\
\hline Turn frequency & 0.264 & 0.166 & 1.59 & 0.11 & 0.047 & 0.306 & 0.15 & 0.88 \\
\hline Bite frequency & 0.038 & 0.163 & 0.23 & 0.82 & 0.119 & 0.273 & 0.44 & 0.66 \\
\hline Reward time $_{(\text {d.f } f=139)}$ & 0.005 & 0.211 & $0.00(w)$ & 0.98 & $\mathrm{n} / \mathrm{a}$ & $\mathrm{n} / \mathrm{a}$ & $\mathrm{n} / \mathrm{a}$ & $\mathrm{n} / \mathrm{a}$ \\
\hline Reward bite $_{(\mathrm{d} . \mathrm{f}=170)}$ & 0.037 & 0.115 & 0.32 & 0.75 & $\mathrm{n} / \mathrm{a}$ & $\mathrm{n} / \mathrm{a}$ & $\mathrm{n} / \mathrm{a}$ & $\mathrm{n} / \mathrm{a}$ \\
\hline Path directness & 0.020 & 0.079 & $0.06(S S)$ & 0.80 & -0.091 & 0.065 & $2.18(S S)$ & 0.16 \\
\hline
\end{tabular}

* Estimate of effect (relative difference between means)

** $t$ statistic, unless otherwise stated ( $w=$ Wald; $S S=$ sum of squares)

S.E. = standard error

$\mathrm{n} / \mathrm{a}=$ model not well fitting due to lack of data

d.f. $=$ degrees of freedom 
Fig. 1. Plan view of experimental apparatus upon electrode plate

Fig 2. Changes in the number of passes within $5 \mathrm{~cm}$ of electrodes throughout experimental week plotted by back-transforming estimates of effects to original units of measurement for fitted curve (Rewarded: constant $=1.72$, regression coefficient $=0.068$, error $=0.015$; Unrewarded: constant $=0.12$, regression coefficient $=0.0001$, error $=$ $0.033)$

Fig 3. Changes in the latency of first response to the electrodes throughout experimental week plotted by back-transforming estimates of effects to original units of measurement for fitted curve (Rewarded: constant $=8.18$, regression coefficient $=0.068$, error $=0.027$; Unrewarded: constant $=8.43$, regression coefficient $=0.004$, error $=0.037$ )

Fig. 4a and b. Changes in number of turn and bite responses to electrodes throughout experimental week plotted by back-transforming estimates of effects to original units of measurement for fitted curve (Turns - Rewarded: constant $=1.98$, regression coefficient $=$ 0.005 , error $=0.008$; Unrewarded: constant $=1.72$, regression coefficient $=0.151$, error $=$ 0.014; Bites - Rewarded: constant $=1.67$, regression coefficient $=0.094$, error $=0.011$; Unrewarded: constant $=1.39$, regression coefficient $=0.205$, error $=0.021$ )

Fig. 5a and b. Changes in the time and bite number after which rewarded catsharks acquired food reward throughout experimental week plotted by back-transforming estimates of effects to original units of measurement for fitted curve (Time: constant $=$ 7.18 , regression coefficient $=0.084$, error $=0.029$; Bite: constant $=1.64$, regression coefficient $=0.072$, error $=0.018$ )

Fig. 6. Changes in path directness to electrodes throughout experimental weeks plotted by back-transforming estimates of effects to original units of measurement for fitted curve (Rewarded: constant $=1.90$, regression coefficient $=0.068$, error $=0.029$; Unrewarded: constant $=1.61$, regression coefficient $=0.014$, error $=0.035), *$ index calculation provided in methods.

Fig. 7. Examples of individual catshark search paths throughout experimental week (i to v) when rewarded and unrewarded. $\mathrm{C}=$ catshark start position; $\mathrm{E}=$ electrode position; P.D. = path directness (rounded figures) 


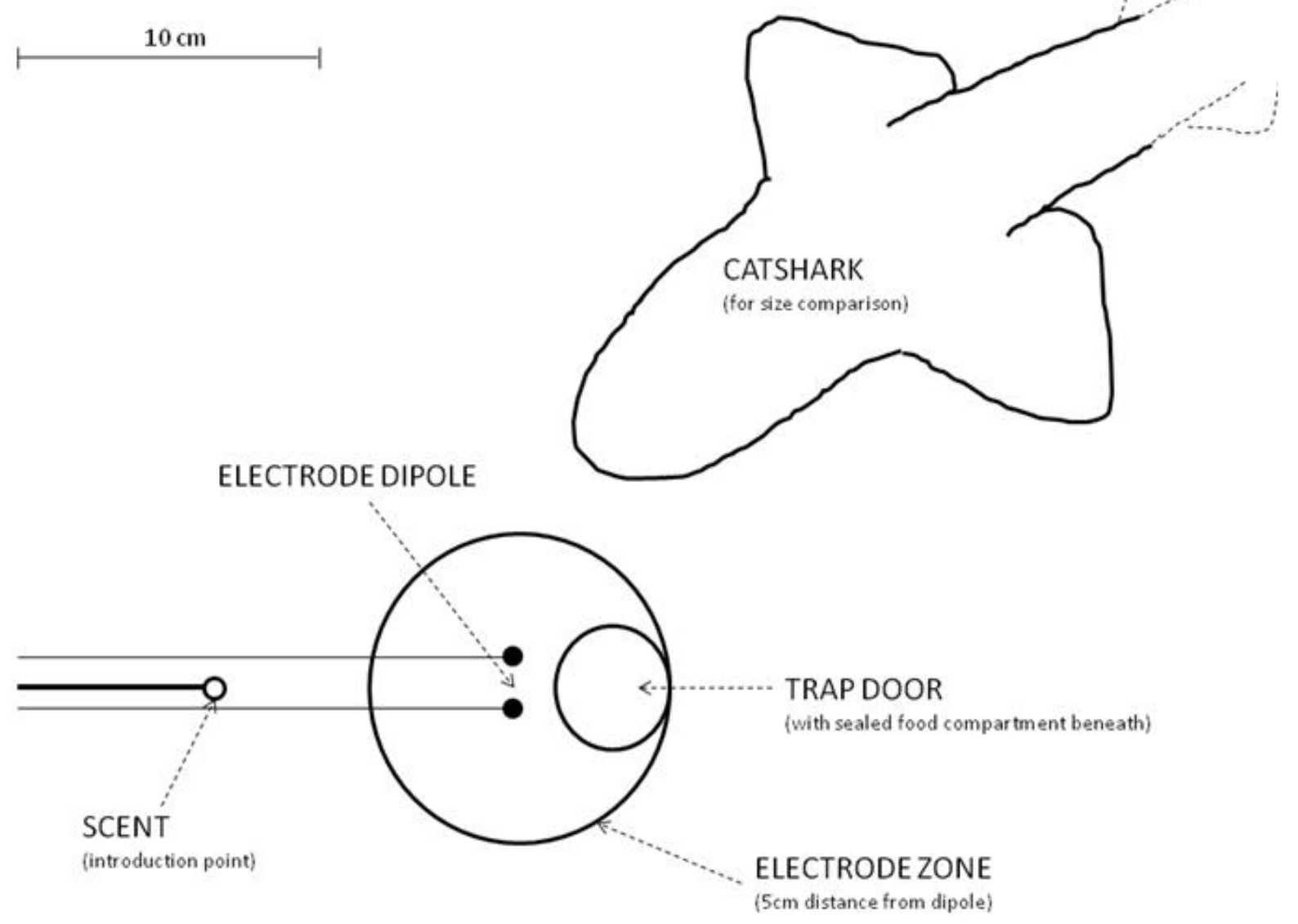




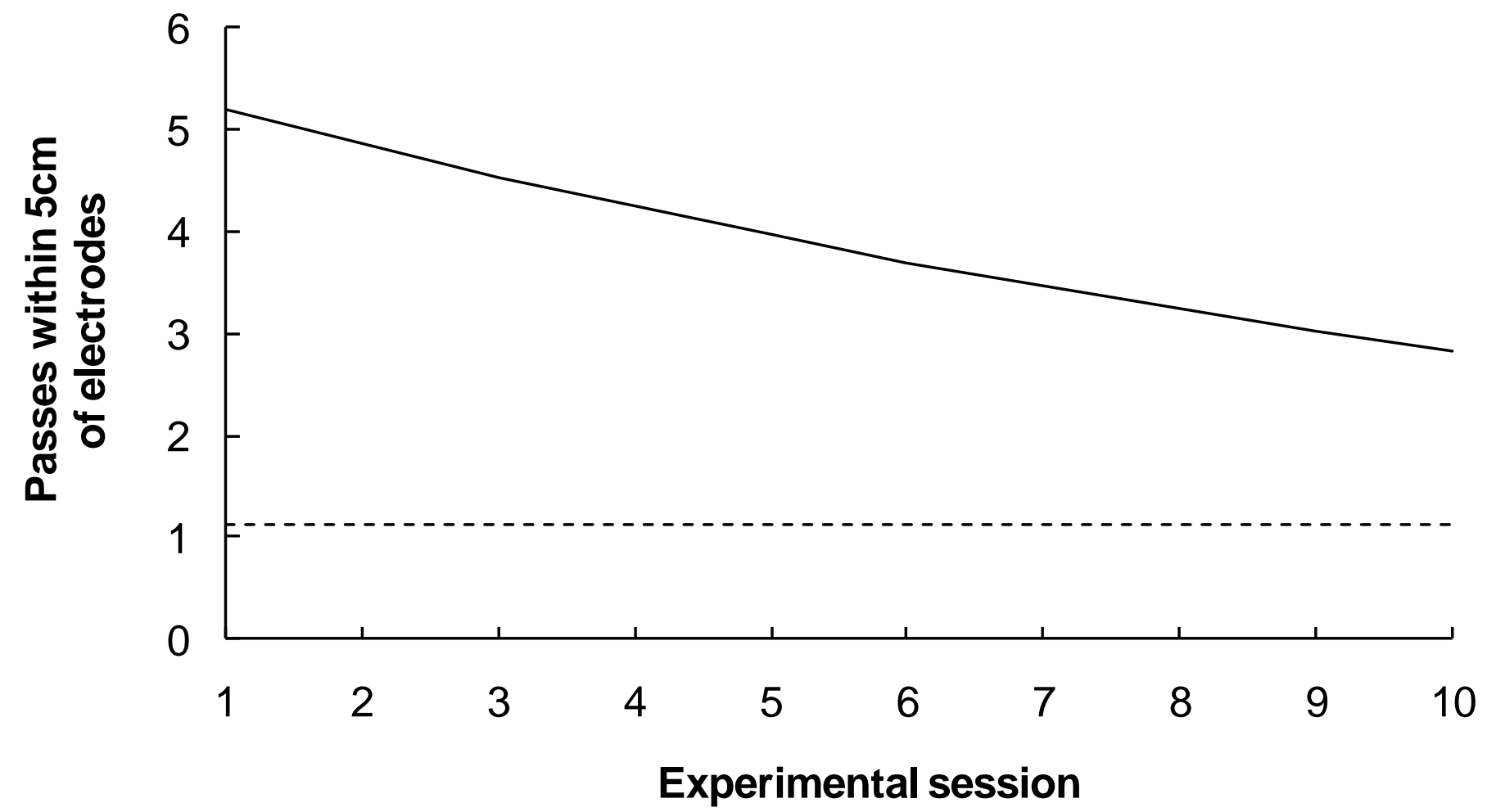

Rewarded - - - - Unrewarded 


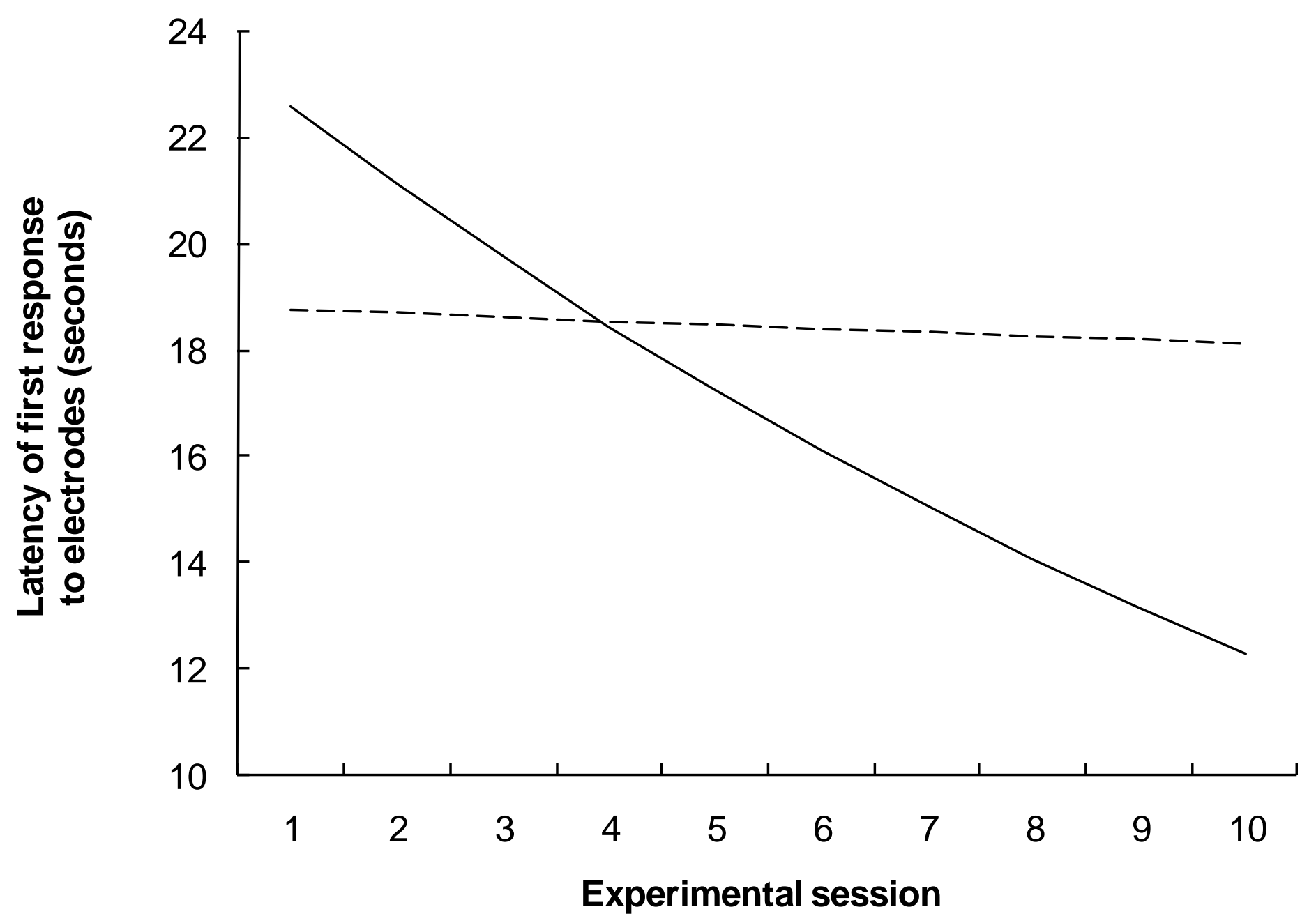



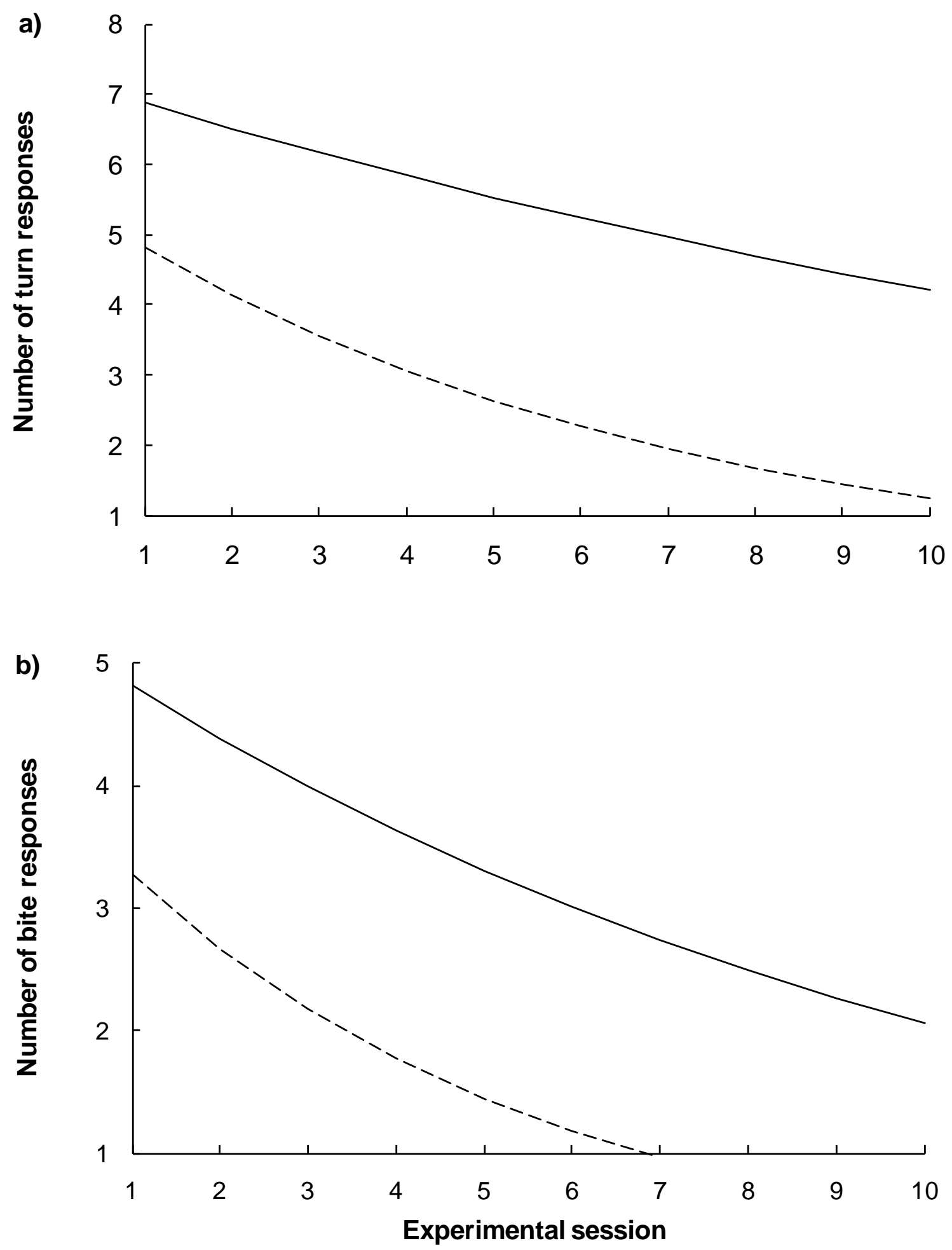

— Rewarded ---. Unrewarded 

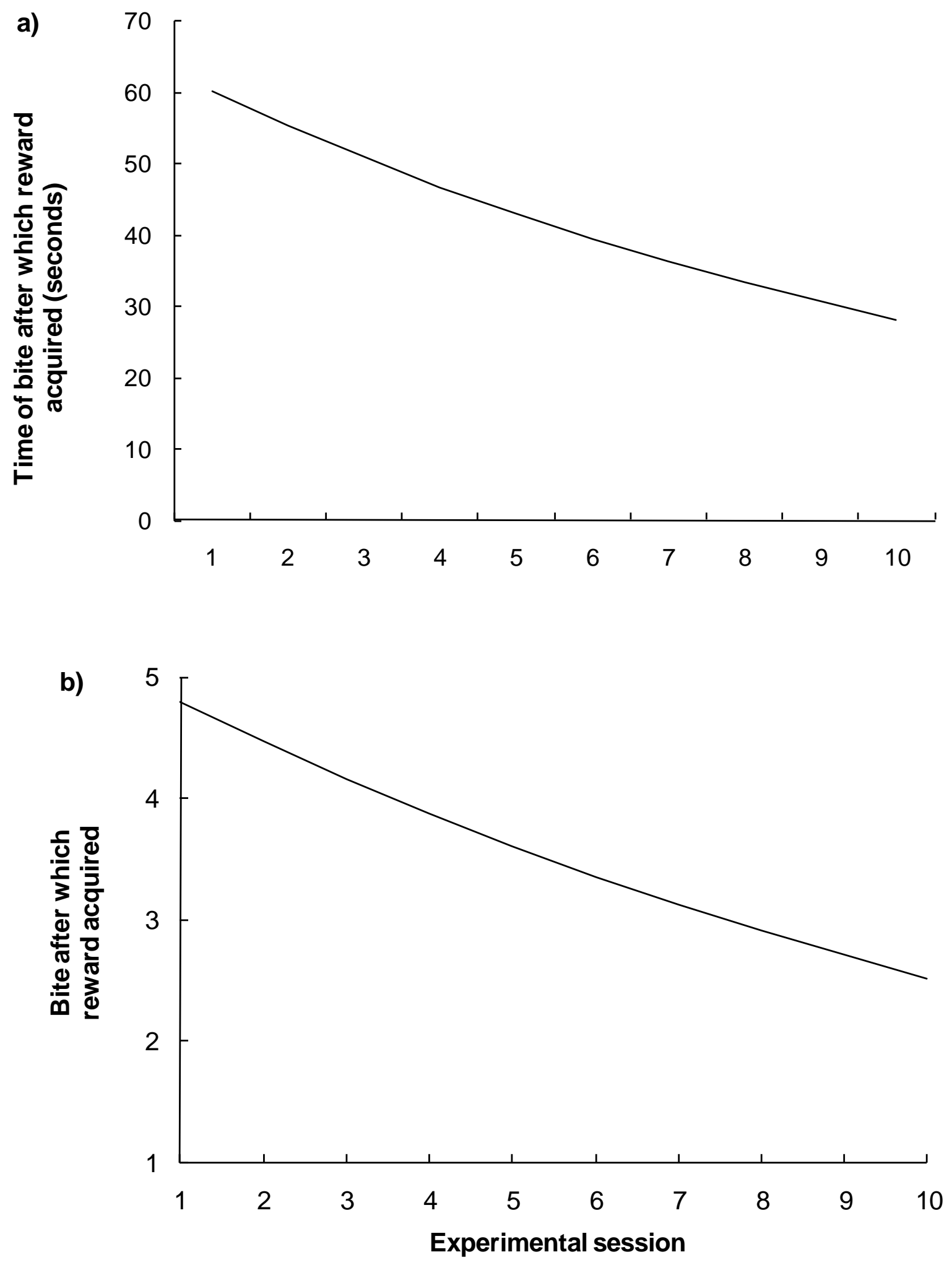


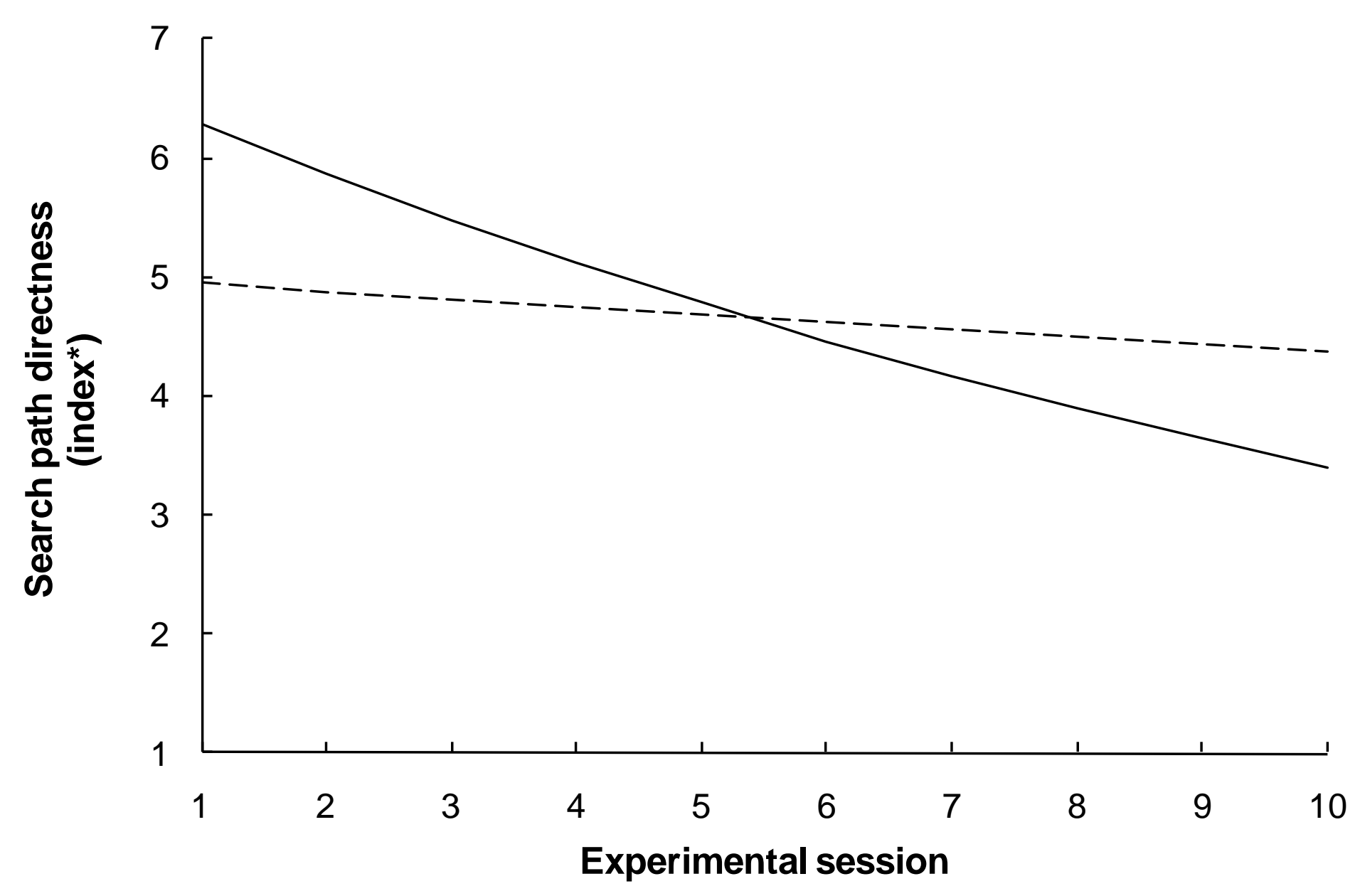

- Rewarded - - - Unrewarded 
Figure 7

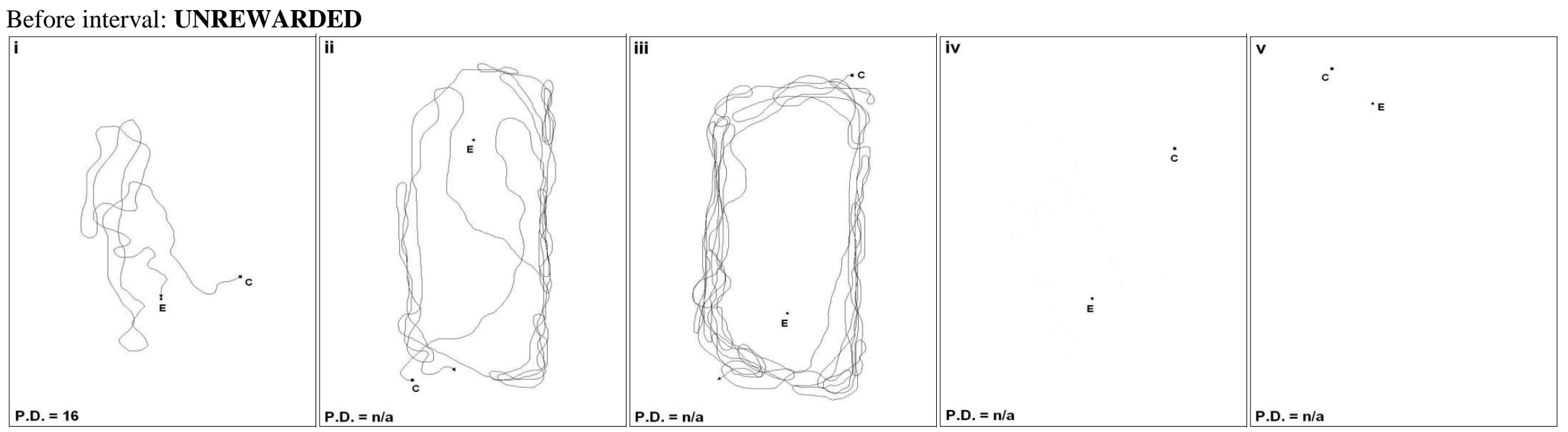

After interval: REWARDED

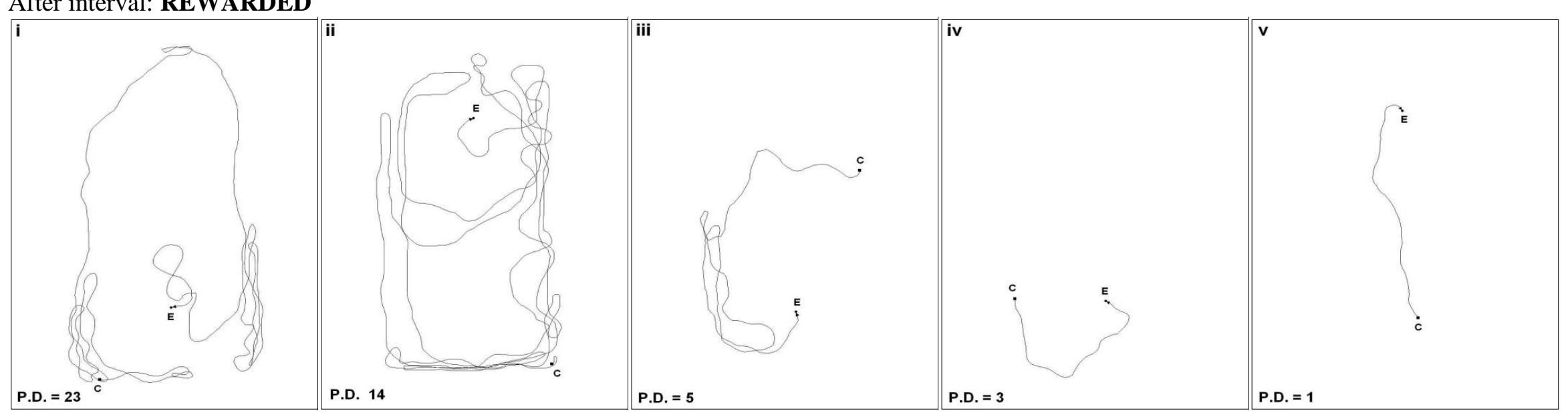

Catshark Blue 1501 
Before interval: REWARDED:

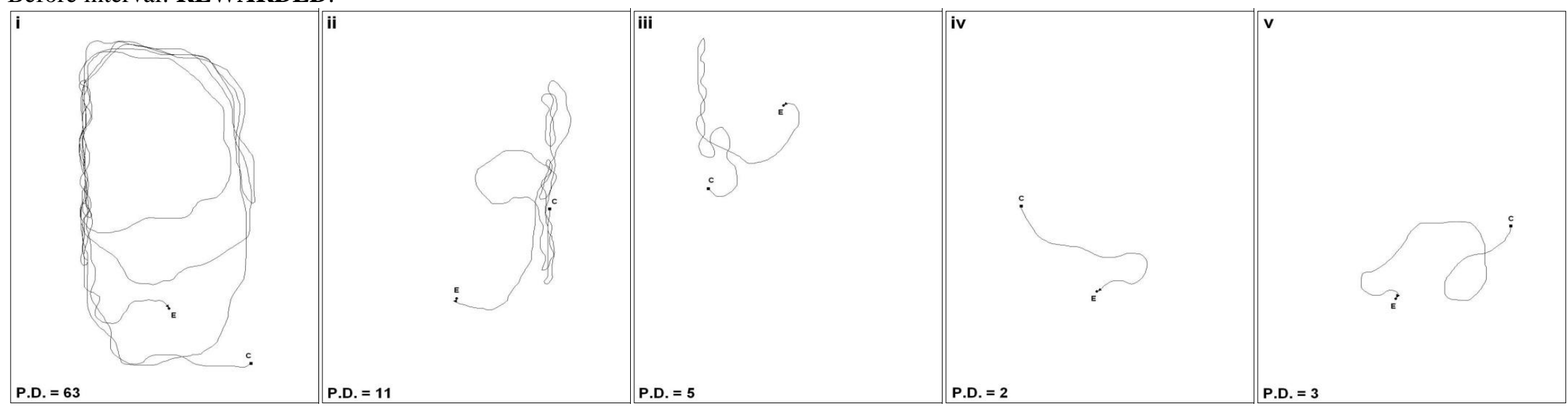

After interval: UNREWARDED:

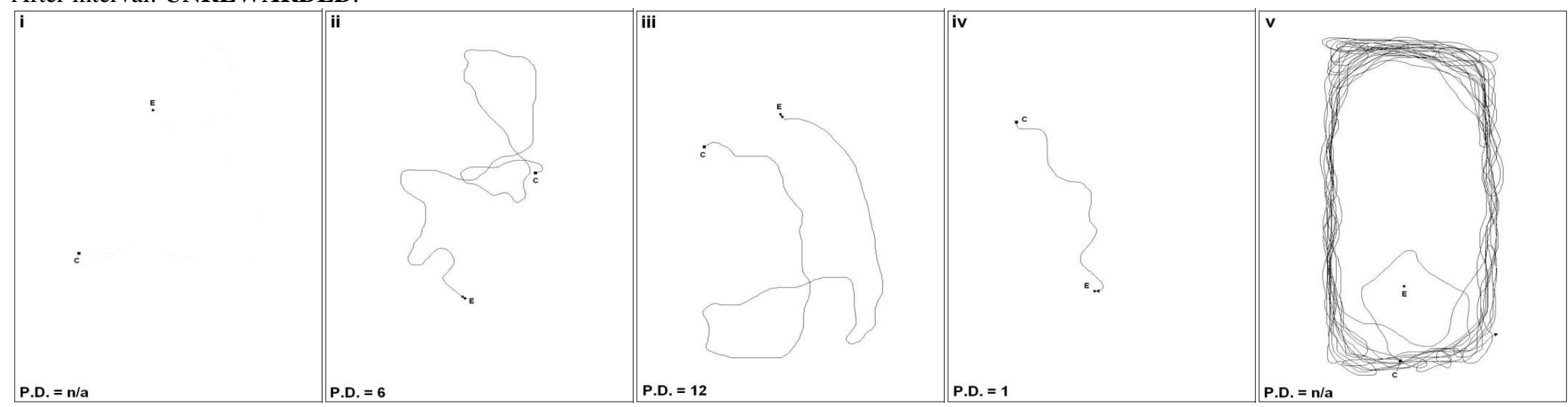

Catshark Green 230 